\title{
Gender aspects in the biochemical control of acromegaly: evaluation of 607 cases from the Austrian Acromegaly Register
}

Greisa Vila ${ }^{1}$, Harald Dobnig'2 ${ }^{2}$ Engelbert Knosp ${ }^{3}$, Christoph Schnack ${ }^{4}$, Holger Franz ${ }^{5}$, Gerd Finkenstedt ${ }^{6}$, Georg Leb ${ }^{2}$, Anton Luger ${ }^{1}$ and the participants of the Austrian Acromegaly Register*

${ }^{1}$ Division of Endocrinology and Metabolism, Department of Internal Medicine III, Medical University of Vienna, Austria, ${ }^{2}$ Department of Internal Medicine, Division of Endocrinology and Metabolism, Medical University of Graz, Austria, ${ }^{3}$ Department of Neurosurgery, Medical University of Vienna, Austria, ${ }^{4}$ Department of Internal Medicine I, Rudolfstiftung Hospital, 1030, Vienna, Austria, ${ }^{5}$ Lohmann and Birkner Health Care Consulting, Berlin, Germany, ${ }^{6}$ Department of Internal Medicine, Medical University of Innsbruck, Austria

\section{Aims and Methodology}

The Austrian Acromegaly Register is an initiative of the Austrian Society for Endocrinology and Metabolism, formally established in 2005. Data are collected by two trained nurses, who visit all centers and continuously entered in a database managed by Lohmann \& Birkner, Berlin, Germany.

We analyzed the data collected within the Austrian Acromegaly Register till the end of 2013. Here we report gender-specific differences in the presentation, therapy and biochemical control of acromegaly in patients included in this registry.

Data on biochemical control were collected in 476 patients with acromegaly and disease duration longer than 9 months, who were last visited between 2003 and 2014. Disease control was evaluated by GH less than $1.0 \mathrm{ng} / \mathrm{ml}$ during an oral glucose suppression test and/or normal ageand gender-specific IGF-1. Outcome data were available for 418 patients.

\section{RESULTS}

\section{Study Population}

At the time of data lock, 607 patients had been enrolled, 329 females and 278 males. Patients were followed for $10.7 \pm 9$ years (range $0-50$ ), with a total of 6470 PatientYears.
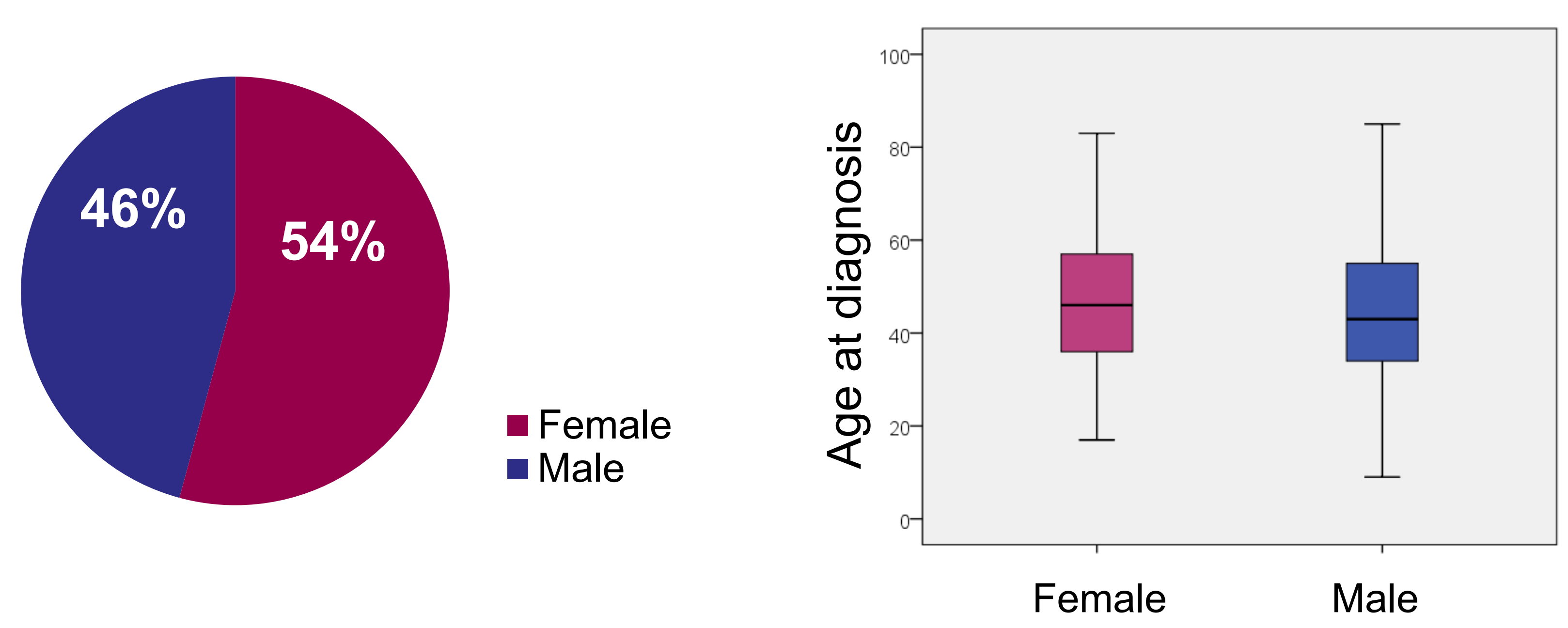

Tumor Size

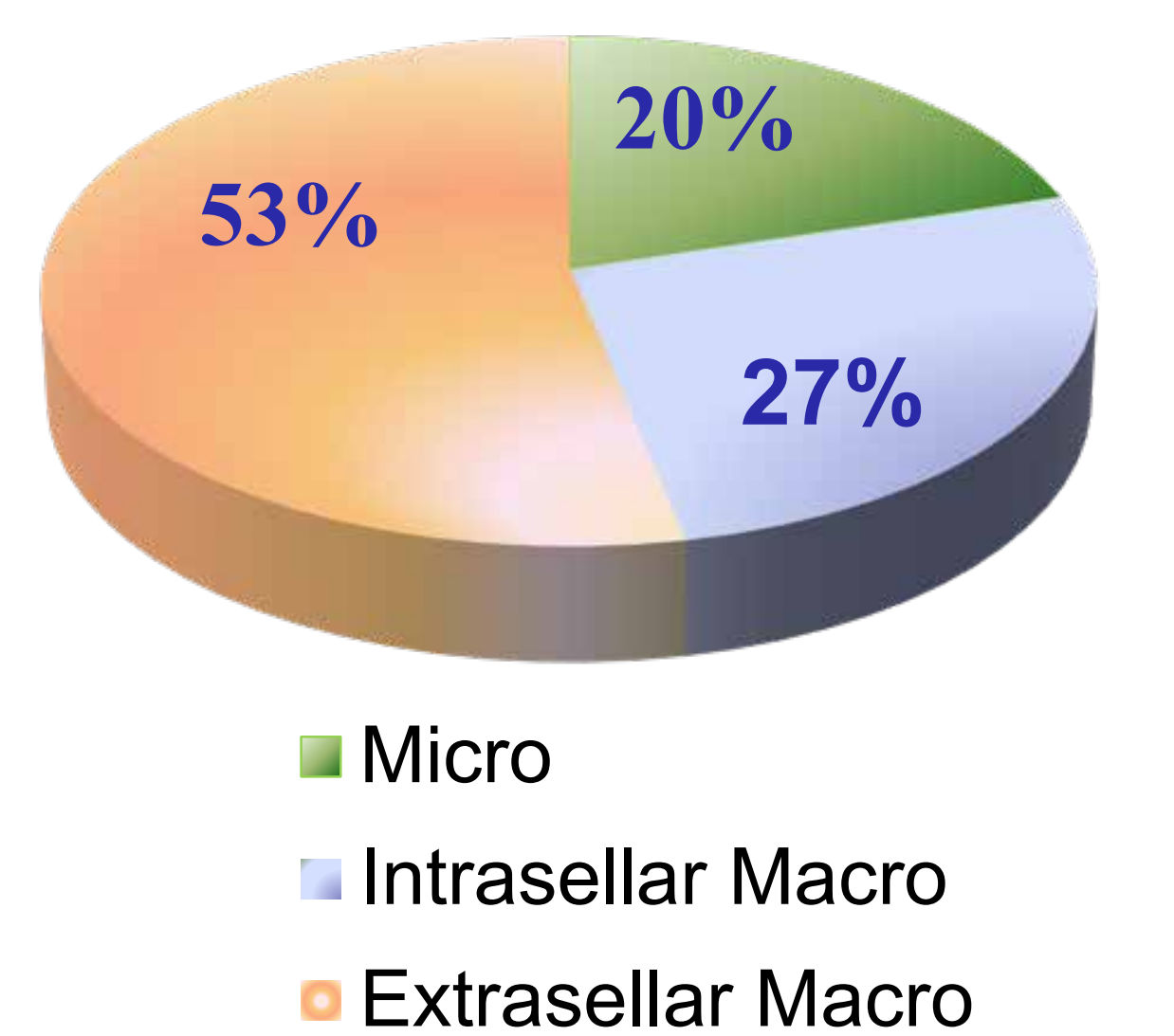

\begin{tabular}{|l|c|c|}
\hline Tumor type & Female (\%) & Male (\%) \\
\hline Microadenoma & 22 & 18 \\
\hline $\begin{array}{l}\text { Intrasellar } \\
\text { macroadenoma }\end{array}$ & 28 & 24 \\
\hline $\begin{array}{l}\text { Extrasellar } \\
\text { macroadenoma }\end{array}$ & 50 & 58 \\
\hline
\end{tabular}

Younger age and male gender at diagnosis of acromegaly are associated with larger tumour size $(P=0.001)$.

\section{Higher prevalence of comorbidities in women}

\begin{tabular}{|l|c|c|c|}
\hline & Diabetes & Hypertension & Diabetes + Hypertension \\
\hline Female (\%) & 29 & 50 & 20 \\
\hline Male (\%) & 24 & 45 & 15 \\
\hline
\end{tabular}

\section{Acknowledgements}

We thank all participating centers and patients.

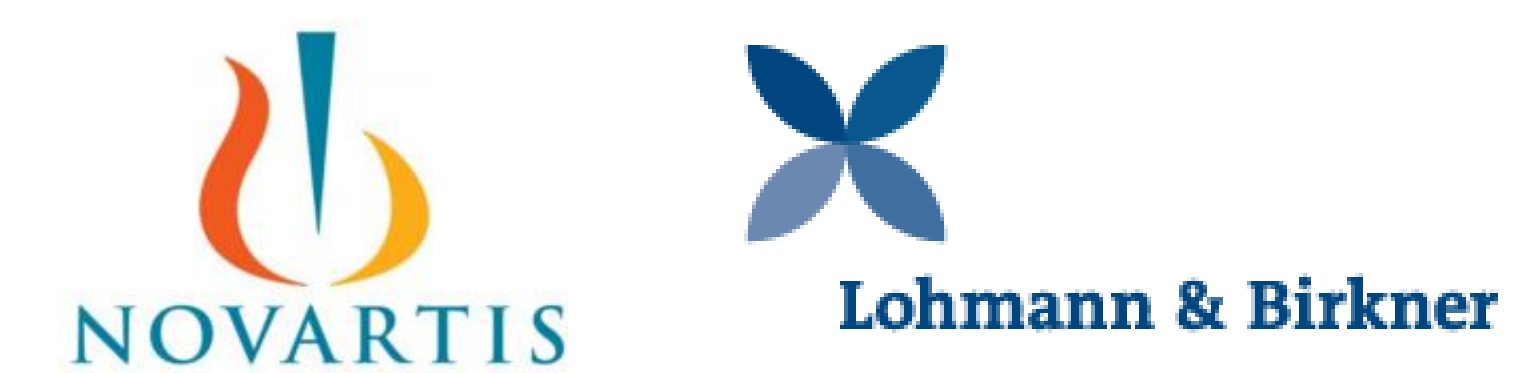

\author{
$[89 \%$ surgery ( $73 \%$ one operation, $10 \%$ two \\ Therapy $11.4 \%$ first line medical therapy \\ $44 \%$ on medical therapy at the last visit \\ $22.4 \%$ radiotherapy, $1.8 \%$ only radiotherapy
}

\section{Gender differences in biochemical control}

\section{Medical Therapy}

$50 \%$ of females and $62 \%$ of males with biochemically controlled disease receive concomitant medical therapy for acromegaly

$62 \%$ of patients receiving concomitant medical therapy are biochemically controlled

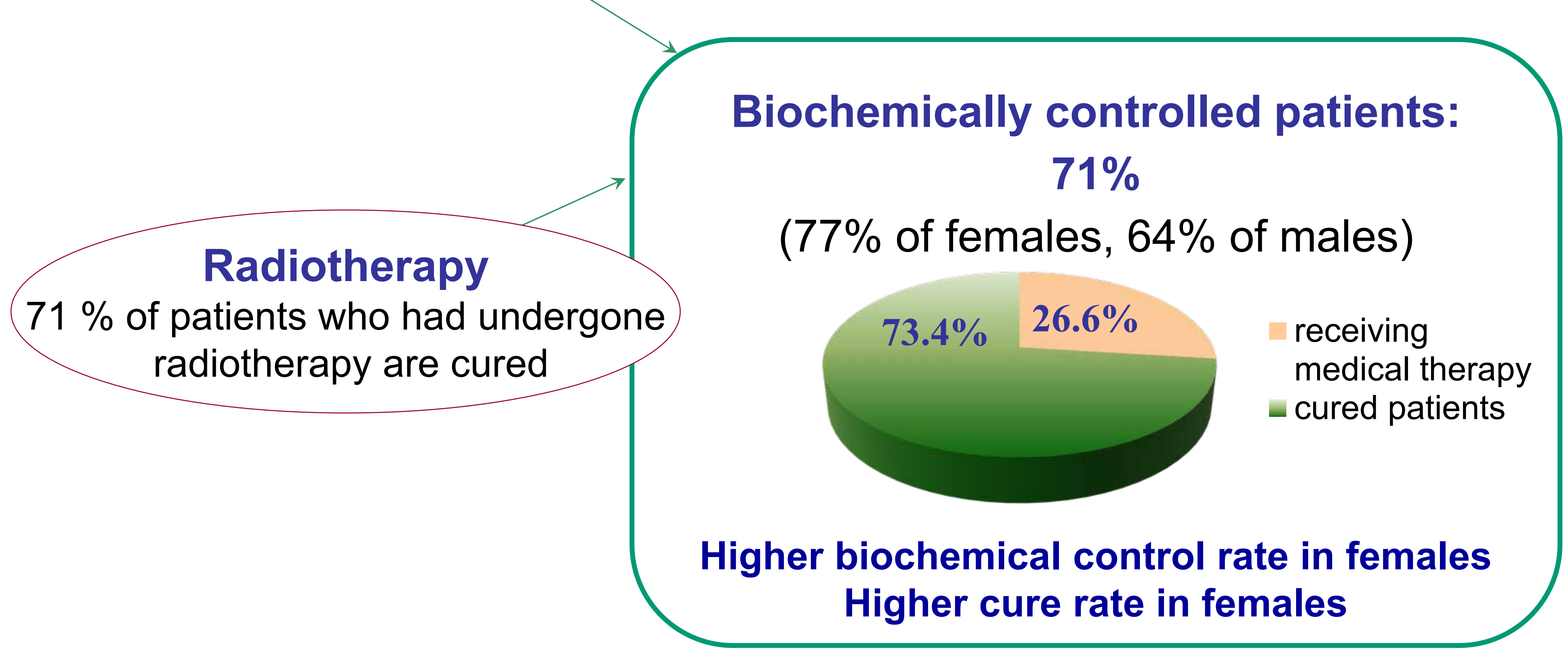

\section{Mortality rates}

Mortality rates were $2.9 \%$ in males and $3.3 \%$ in females, but mean age at death was 63 years for men and 73 years for women.

\section{${ }^{*}$ Centers and Patients}

Medical University of Vienna (230 pt), Medical University of Graz (113 pt), Medical University of Innsbruck (69 pt), SALK - St. Johanns Hospital Salzburg (58 pt), General Hospital of Linz (57 pt), Rudolfstiftung Hospital (21 pt), Klagenfurt Teaching Hospital (19 pt), Hanusch Hospital Vienna (12 pt), Donau Hospital Vienna (10 pt), Feldkirch Teaching Hospital (8 pt), Hohenems Teaching Hospital (6 pt). 